\title{
Ten year mortality and causes of death in patients with rheumatoid arthritis
}

\author{
O MUTRU, M LAAKSO, H ISOMÄKI, K KOOTA
}

\begin{abstract}
Five hundred men and 500 women, aged 40 or over, with rheumatoid arthritis, together with a control population matched for age and sex, were observed over 10 years. During that time 352 patients with rheumatoid arthritis ( 208 men, 144 women) and 221 controls (148 men, 73 women) died. The overall mortality was significantly higher $(p<0.0001)$ in both men and women with rheumatoid arthritis than in the controls.

Infections and cardiovascular and renal diseases (especially amyloidosis) appeared to be the main causes of death in rheumatoid arthritis.
\end{abstract}

\section{Introduction}

Most studies of long term survival of patients with rheumatoid arthritis have suggested that mortality is higher in patients with rheumatoid arthritis than in the general population or control subjects without rheumatoid arthritis..$^{1.4}$ It has been established beyond any doubt that an excess of patients with rheumatoid arthritis die from infectious ${ }^{13 \times 10}$ and renal ${ }^{12 \times 10}$ diseases. In some studies an increased mortality from gastrointestinal ${ }^{46411}$ and respiratory $^{t h} 11$ diseases has also been reported. An increased mortality from cardiovascular diseases, particularly from heart diseases, has also been reported, although there is still some controversy about this issue. ${ }^{1.3 \times 11}$ Similarly, an excess of deaths from malignancies in patients with rheumatoid arthritis remains controversial. ${ }^{\mathrm{1} 11.12}$

Most of the studies published so far have been based on small numbers of patients, which may at least partly explain the controversial results concerning causes of death. Several of the previous studies have based assessment of cause specific mortality of patients with rheumatoid arthritis on official mortality statistics for the general population. This approach may raise problems related to the so called "cohort effect," changing cause specific mortality of successive age cohorts of the population.

Here we report the results of a 10 year prospective study to assess the overall mortality and causes of death in a cohort of 1000 subjects with rheumatoid arthritis and 1000 subjects without rheumatoid arthritis. The mortality data for three and five years have already been reported. ${ }^{1+15}$

\footnotetext{
Department of Medicine, Kuopio University Central Hospital, 70210 Kuopio 21 , Finland

O MUTRU, MD, consultant physician

M LAAKSO, MD, lecturer in medicine

Rheumatism Foundation Hospital, Heinola, Finland

H ISOMÄKI, MD, professor in rheumatology

K KOOTA, MD, associate chief physician

Correspondence to: Dr M Laakso.
}

\section{Patients and methods}

A random sample comprising 500 men and 500 women born 31 May 1930 or earlier and alive on 31 May 1970 was taken from among the patients with definite rheumatoid arthritis treated at the Rheumatism Foundation Hospital, Heinola, during 1959-68. The diagnosis was based in every case on a hospital examination and the criteria of the American Rheumatism Association. A cohort of 500 men and 500 women matched for sex and age \pm 1 year $)$ and without rheumatoid arthritis was randomly selected from the National Social Security Code Register comprising the whole Finnish population. Because the death rate for subjects living in east Finland differs from that for subjects living in other parts of the country the pairs were also matched according to the part of the country in which they lived. Owing to an inadvertent failure in the maintenance of the original data file, on which the previously published three and five year mortality data had been based, ${ }^{1+15}$ the possibility of linking data on 52 patients with rheumatoid arthritis belonging to the original cohort with mortality register data was lost. These patients were replaced in the present study by 52 other patients randomly drawn from the patients treated at the hospital in 1959-68.

A 10 year follow up of both cohorts with respect to mortality was carried out on the basis of a computer file of the official death certificates kept by the Central Statistical Office of Finland. The underlying cause of death as coded in the death certificates was used in the present analyses. Causes of death were classified into different categories of disease on the basis of the eighth revision of the International Classification of Diseases, ${ }^{16}$ as follows: infectious diseases, 1-136, 320-324, 366-369, 380-384, 460-486, 500-513, 567, 572, 611-622, 710-711, 720; malignant neoplasms, 140-239; cardiovascular diseases, 390-458; all cardiac diseases, 393-429; coronary heart disease, 410 414; cerebrovascular diseases, 430-438; amyloidosis, 276; renal failure (other than amyloidosis), 580-599; accidents and suicides, 800-999.

In Finland payment for drugs used in the treatment of rheumatoid arthritis, ankylosing spondylitis, and chronic systemic connective tissue disease is fully reimbursed according to the Sickness Insurance Act, and the Social Insurance Institution keeps a special computer file on the patients affected. On the basis of this register none of the controls had rheumatoid arthritis, ankylosing spondylitis, or chronic systemic connective tissue disease at the beginning of follow up. The incidence of new cases of rheumatoid arthritis during the 10 years among the controls could be calculated also on the basis of this register.

Survival analysis statistics for all causes of death and for different categories of disease were calculated using the so called $\mathrm{D}$ algorithm of Lee and Desu. ${ }^{17} \mathrm{D}$ is asymptomatically distributed as $\chi^{2}$ with $(\mathrm{g}-1)$ degrees of freedom, where $g$ equals the number of groups, under the null hypothesis that the subgroups are samples from the same survival distribution. When $D$ was calculated for certain categories of disease all other diagnoses were classified as censored observations.

\section{Results}

Table I shows age at the beginning of follow up for subjects with and without rheumatoid arthritis. Two men and nine women without rheumatoid arthritis developed rheumatoid arthritis during follow up, giving a 10 year incidence of $1 \cdot 1 / 1000$ for rheumatoid arthritis $(0 \cdot 4 / 1000$ for men, $1 \cdot 8 / 1000$ for women). These subjects were excluded from further analyses. Mean (SEM) age at the beginning of follow up was 54.5 (0.4) (range 40-87) years for men with rheumatoid arthritis and $55 \cdot 1(0 \cdot 4)$ (range $40-87$ ) years for male controls. The corresponding values for women were 55.5 (0.4) (range 40-80) and $56 \cdot 2(0 \cdot 4)$ (range $40-80)$ years, respectively. 
During the 10 years of follow up $208(42 \%)$ of the men with rheumatoid arthritis and $144(29 \%)$ of the male controls died. The corresponding values for women were $148(30 \%)$ and $73(15 \%)$, respectively. Necropsy was performed in $66(32 \%)$ men with rheumatoid arthritis, $53(37 \%)$ male controls, $40(27 \%)$ women with rheumatoid arthritis, and $26(36 \%)$ female controls. The figure shows the cumulative survival curves for subjects with and without rheumatoid arthritis by sex. Rheumatoid arthritis shortened life significantly in both sexes during the follow up period (significance of $D$, $\mathrm{p}<0.0001$ ).

Table II shows the causes of deaths for subjects with and without rheumatoid arthritis. The significance of the differences between the groups was assessed over the 10 years by survival analysis statistics $(D)$ in both

\begin{tabular}{|c|c|c|c|c|}
\hline \multirow{2}{*}{$\begin{array}{l}\text { Age } \\
\text { (years) }\end{array}$} & \multicolumn{2}{|c|}{ Men } & \multicolumn{2}{|c|}{ Women } \\
\hline & Patients & Controls* & Patients & Controls* \\
\hline 40.44 & 54 & +6 & 59 & 53 \\
\hline $45-49$ & 103 & 103 & 70 & $65 \quad 68$ \\
\hline 50.54 & 84 & $78 \quad 80)$ & 87 & 8283 \\
\hline 55.59 & 119 & 114 & 115 & 112 \\
\hline $60-64$ & 91 & 96 & 98 & $98(102)$ \\
\hline $65-69$ & 39 & 49 & 56 & $61 \quad 62$ \\
\hline$\geqslant 70$ & 10 & 12 & 15 & 20 \\
\hline Total & 500 & $498(500)$ & 500 & $491(500)$ \\
\hline
\end{tabular}

*Subiects who developed rheumatoid arthritis during follow up excluded (total number of controls in parentheses). criticism because they are based on patients admitted to hospital with established disease who may therefore have a relatively complicated form of rheumatoid arthritis. ${ }^{18}$ This may also be true with respect to our series of patients with rheumatoid arthritis from the Rheumatism Foundation Hospital.

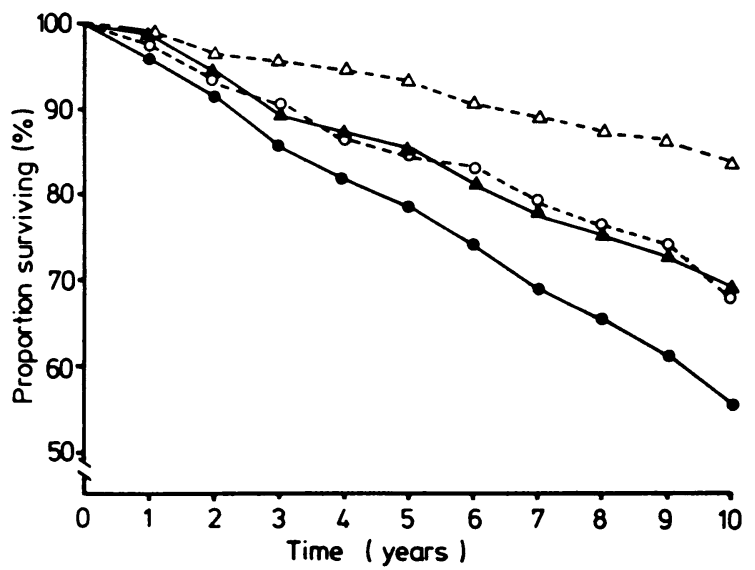

Survival (\%) for all causes of death by the Lee and Desu algorithm in patients with rheumatoid arthritis (men: controls without rheumatoid arthritis (men: $\mathrm{O}--\mathrm{O}$; women: $\Delta--\triangle)$

TABLE II-Causes of deaths of subjects with and without rheumatoid arthritis (patients and controls) by sex. Data indicate numbers of subjects with numbers of necropsies in parentheses

\begin{tabular}{|c|c|c|c|c|c|c|}
\hline \multirow[b]{2}{*}{ Causes of death } & \multicolumn{2}{|c|}{ Men } & \multirow[b]{2}{*}{$\mathrm{p} \dagger$} & \multicolumn{2}{|c|}{ Women } & \multirow[b]{2}{*}{ pt } \\
\hline & Patients & Controls* & & Patients & Controls & \\
\hline Infection: & 113 & $4(1)$ & 0.0482 & $25(6)$ & $4(0)$ & $<0.0001$ \\
\hline Respiratory & $8 \quad 2$ & +1 (1) & & & $4(0)$ & \\
\hline Other & 31 & 0 & & $4(2)$ & 0 & \\
\hline Malignant neoplasm & $28 \quad 8$ & $367)$ & 0.3941 & $14(4)$ & $22(4)$ & $0 \cdot 2570$ \\
\hline Cardiovascular disease: & $115(35)$ & $78(25)$ & 0.0009 & $51(15)$ & $41(19)$ & 0.1851 \\
\hline Coronary heart disease & $71(20)$ & $59(19)$ & $0 \cdot 1026$ & 20 (11) & $21(13)$ & 0.9017 \\
\hline Cerebrovasciular disease & 173 & $13(3)$ & & 12 (2) & $12(3)$ & \\
\hline Other & $27(12)$ & $6(3)$ & & 19 (2) & $8(3)$ & \\
\hline Renal failure: & 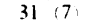 & 2 (1) & $<0.0001$ & 42 (II) & 0 & $<0.0001$ \\
\hline Amvloidosis & 1214 & 10 & $<0.0001$ & $19(7)$ & 0 & $<0.0001$ \\
\hline Other & $19(3)$ & i (1) & $<0.0001$ & $23(4)$ & 0 & $<0.0001$ \\
\hline Accidents and suicides & 6 is & $14(14)$ & & $5(2)$ & $3(2)$ & \\
\hline Other & $17 \quad(8)$ & $9(5)$ & & $11(2)$ & 3 (1) & \\
\hline Total & $208(66)$ & $144(53)$ & $<0.0001$ & $148(40)$ & $73(26)$ & $<0.0001$ \\
\hline
\end{tabular}

*Cause of death unknown for one patient.

†Significance of survival statistics between patients and controls.

sexes, and the significance of D is shown for the most important causes of death. Deaths from infectious diseases were significantly more common in patients with rheumatoid arthritis than in controls $(p=0.0482$ for men, $\mathrm{p}<0.0001$ for women) and most were due to respiratory infections. No difference in the occurrence of deaths from malignant neoplasms was observed between the groups. Men with rheumatoid arthritis showed a significantly higher incidence of cardiovascular deaths than did the corresponding control group ( $p=0.0009)$, but no difference in this respect was observed in women. All types of deaths from cardiac disorders were also more common in men with rheumatoid arthritis than in male controls $(p=0.0044)$, but no difference between the groups was observed with respect to coronary heart disease. Both men and women with rheumatoid arthritis died significantly more often from amyloidosis and other causes of renal failure than did corresponding controls $(p<0.0001)$. No difference between the subjects with and without rheumatoid arthritis was observed in deaths from accidents and suicides.

\section{Discussion}

Life expectancy was appreciably shorter for our cohort of patients with definite or classic rheumatoid arthritis than for the controls, confirming the experience of many former studies. ${ }^{1.9}$ Most of these studies have reported, however, on hospital series and are open to
It has been argued that a further source of error in results may be the selection of suitable controls. ${ }^{1 \times}$ The use of a control population matched individually with the patients by sex and age may introduce an error by selection, especially if the controls are chosen for their freedom from rheumatoid arthritis. In our study therefore the overall mortality and cardiovascular mortality rates of the control groups were compared with those computed on the basis of the statistics on death for the general population of Finland, applying the appropriate mortality rates in 1975 to the age and sex specific person years. In both sexes there was no difference in mortality between our control groups and the Finnish general population.

A high occurrence of deaths from infectious diseases in patients with rheumatoid arthritis was found in our series in accordance with most of the earlier studies. ${ }^{138.10}$ Most deaths from infectious diseases were of respiratory origin, especially in women. The reasons for susceptibility to infectious diseases in patients with rheumatoid arthritis are largely unknown; but it has been argued that this susceptibility might be due to a primary defect of the immunological system in rheumatoid arthritis, an acquired defect of the immune response, or a non-specific decrease in the resistance to infectious diseases which may occur in any chronic disease. ${ }^{14}$

No significant difference in the occurrence of deaths from 
malignant neoplasms was found over the follow up period between the subjects with and without rheumatoid arthritis, although the proportion of deaths from malignancies was higher in subjects without rheumatoid arthritis. In some studies a greater incidence of malignant diseases in patients with rheumatoid arthritis has been reported, ${ }^{+1112}$ but in general the proportion of deaths from malignant diseases has been similar or lower in subjects with rheumatoid arthritis than in subjects without rheumatoid arthritis. ${ }^{36420}$ The low proportion of deaths due to cancer in patients with rheumatoid arthritis does not seem to be due to a lower morbidity in cancer because in some studies an excess risk of lymphomas, leukaemia, and myeloma has been reported. ${ }^{212}$

An increased incidence of deaths from cardiac causes has been reported in some studies ${ }^{+6 \times 10}$ but not in all..$^{1313}$ Our analyses showed a significant increase in cardiovascular deaths in men with rheumatoid arthritis compared with male controls, but no such excess was found in women with rheumatoid arthritis. It has been suggested that the use of aspirin, which reduces platelet adhesiveness and the formation of thrombus and atheroma, protects from cardiac deaths in patients with rheumatoid arthritis. ${ }^{232+}$ Our results do not support this hypothesis. The proportion of deaths from congestive heart failure in our study was higher in patients with rheumatoid arthritis than in controls. Perhaps patients with rheumatoid arthritis have a diffuse myocardial involvement, ${ }^{\text {" }}$ such as fibrosis, which may cause the deterioration of left ventricular function.

The most appreciable differences in the causes of deaths between subjects with rheumatoid arthritis and without rheumatoid arthritis were due to renal failure and amyloidosis. Although $12(6 \%)$ of the men with rheumatoid arthritis and 19 (13\%) of the women with rheumatoid arthritis died from renal amyloidosis, there suill remained a higher proportion of deaths from other causes of renal failure. This fact raises a serious question of the renal side effects of drugs used to treat rheumatoid arthritis. ${ }^{2 \hbar}$ Gold $^{272 x}$ and penicillamine ${ }^{24}{ }^{30}$ both have severe renal side effects, and deterioration of renal function has been observed in patients with rheumatoid arthritis treated with aspirin." Haematuria and mild mesangial glomerulonephritis have also been detected, however, in patients with rheumatoid arthritis independently of gold or penicillamine treatment. ${ }^{32}$ The risk for renal involvement posed by many of the new anti-inflammatory analgesics is not known. ${ }^{33}$

In conclusion, this large scale, prospective, cohort study of 1000 subjects with rheumatoid arthritis and 1000 subjects without rheumatoid arthritis shows that the life expectancy of patients with rheumatoid arthritis is considerably reduced. Infections and cardiovascular and renal diseases are the main causes of death in rheumatoid arthritis.

\section{References}

I Cobb $S$, Anderson F, Bauer W. Length of life and cause of death in rheumatoid arthritis. N Englf Med 1953;249:553-6.

2 Dutchie JJR, Brown PE, Truetove LH, Baragar FD, Lawric AJ. Course and prognosis in rheumatoid arthritis: a further report. Ann Rheum Dis 1964;23:193-202.

3 Uddin J, Kraus AS, Kelly HG. Survivorship and death in rheumatoid arthritis. Arthrtis Rheum 1970;13:125-30.

4 Monson RR, Hall AP. Mortality among arthritics. $f$ (Chronc Dis 1976;29:459-67.

5 Allebeck P, Ahlbom A, Allander E. Increased mortality among persons with rheumatoid arthritis,

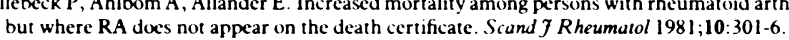

6 Allebeck P. Increased mortality in rheumatoid arthritis. Scand J Rheumatol 1982;11:81-6.

6 Allebeck P. Increased mortality in rheumatoid arthritis. Scand f Rheumatol 1982;1 7 Abruz:zo JL. Rheumatoid arthritis and mortality. Arthrits Rheum 1982;25:1020-3.

8 Prior P, Symmons DPM, Scott DL, Brown R, Hawkins CF. Cause of death in rheumatoid arthritis. Br $\mathcal{J}$ Rheumutol 1984;23:92-9.

Vandenbroucke JP, Hazevoet HM, Cats A. Survival and cause of death in rheumatoid arthritis: a 25-year prospective follow up. $\mathcal{I}$ Rheumatol 1984;11:158-61.

10 Rasker JJ, Cosh JA. Cause and age at death in prospective study of 100 patients with rheumatoid arthritis. Ann Rheum Dis 1981;40:115-20.

11 Lewis P, Hazleman BL, Hanka B, Roberts S. Cause of death in patients with rheumatoid arthritis with particular reference to azathioprine. Ann Rheum Dis 1980;39:457-61.

12 Moesmann G. Malignancy and mortality in subacute rhcumatoid arthritis in old age. Acta Rheumatol Scand 1969;15:193-9.

13 Linos A, Worthington JW, O'Fallon WM, Kurland LT. The epidemiology of rheumatoid arthritis in Rochester, Minnesota: a study of incidence, prevalence and mortality. Am J Epidemiol 1980;111:87-8.

14 Isomaki $\mathrm{H}$, Mutru $\mathrm{O}$, Koota $\mathrm{K}$. Death rate and causes of death in patients with rheumatoid arthritis. Scand J Rheumatol 1975;4:205-8.

$15 \mathrm{~K}$ cota $\mathrm{K}$, Isomäki $\mathrm{H}$, Mutru $\mathrm{O}$. Death rate and causes of death in $\mathrm{RA}$ patients during a period of five years. Scand 7 Rheumutol 1977;6:241-4

16 World Health Organisation. Intermutional classification of diseuses. 8th revision, 1965. Geneva: WHO, 1967

17 Lee E, Desu $M$. A computer program for comparing k samples with right-censored data. Compuler Programs in Biomedicine 1972;2:315-21.

18 Cosh JA. Survival and death in rheumatoid arthritis. 7 Rheumutol 1984;11:117-8.

19 Baum J. Infection in rheumatoid arthritis. Arthritis Rheum 1971;14:135-7.

20 Mutru $\mathrm{O}$, Koota K, Isomäki H. Causes of death in autopsicd RA patients. Sicand $\mathcal{J}$ Rheumatol 1976;5:239-40.

21 Isomaki $\mathrm{H}$, Hakulinen $\mathrm{T}$, Joutsenlahti $\mathrm{U}$. Excess risk of lymphomas, leukaemia and myeloma in patients with rheumatoid arthritis. $\mathcal{J}$ Chronic Dis 1978;31:691-6.

22 Prior $\mathrm{P}$, Symmons DPM, Hawkins CF, Scott DL, Brown $\mathrm{R}$. Cancer morbidity in rheumatoid arthritis. Ann Rheum Dis 1984;43:128-31.

23 Czaplicki S, Gietka J, Sulck K. The frequency of coronary heart disease and myocardial infarction in rheumatoid arthritis patients. Cor V'usa 1978;20:249-54.

24 Davis RF, Engleman EG. Incidence of myexardial infarction in patients with rheumatoid Davis RF, Engleman EG. Incidence of
arthritis. Arthrits Rheum 1974:17:527-33.

25 Bonfiglio $\mathrm{T}$, Atwater EC. Heart disease in patients with seropositive rheumatoid arthritis. Arch Intern Med 1969;124:714-9.

26 Lawson AAH, MacLean N. Renal disease and drug therapy in rheumatoid arthritis. Ann Rheum Dis 1966;25:441-9.

27 Vaamonde CA, Hunt FR. The nephrotic syndrome as a complication of gold therapy. Arthrtis Rheum 1970;13:826-34.

28 Blackwell MR, Hall CL, Tribe CR, Bacon PA. Gold induced nephropathy. Ann Rheum Its $1981 ; 40: 525$.

29 Bacon PA, Tribe CR, Mackenzic JR, Verrier-Jone J, Cumming RH, Amer B. Penicillamine nephropathy in rheumatoid arthritis. $Q \mathcal{J}$ Med 1976;45:661-84.

30 Day TA, Golding JR. Hazards of penicillamine therapy in the treatment of rheumatoid arthritis. Postgrad Med J 1974:50 (suppl 2):71-3.

31 Kimberly RP, Plot\% PH. Aspirin-induced depression of renal function. $N$ Engl 7 Med 1977;296:418-24.

32 Hordon LD, Sellars L, Morley AR, Wilkinson R, Thompson M, Griffiths ID. Haematuria in rheumatoid arthritis: an association with mesangial glomerulonephritis. Ann Rheum Dis
ren 1984:43:440-3

33 Anonymous. Aspirin and renal function [Editorial]. Lancet 1977;i:942-3.

(Accipled 28 Februan 1985,

\section{Is it safe to drink milk when on holiday in the countries of the Mediterranean?}

It is not safe to drink raw milk or to consume dairy products that have not been heat treated in the Mediterranean area or in any other countries. Brucellosis and tuberculosis are the most serious diseases likely to be contracted from raw milk products in Mediterranean countries. Brucellosis in the Mediterranean is usually due to Brucella melitensis and was formerly known as Malta fever, although the disease is now eradicated from that island; it is endemic in goats and sheep in many areas. Imported cases in the United Kingdom usually have a history of eating unpasteurised sheep's or goat's cheese. 'Br abortus is commoner in Western Europe and is endemic in cattle, although eradication is nearly complete in England and Wales, ${ }^{2}$ and almost half the cases now reported acquired their infection overseas. The Communicable Disease Surveillance Centre reports that in the five year period 1978-82 there were 15 cases of imported brucellosis due to $\mathrm{Br}$ melitensis and 21 due to $\mathrm{Br}$ abortus. Of the former, eight acquired the infection in the Mediterranean and of the latter, 14 acquired the infection in either the Mediterranean or in Europe. The CDSC is not aware of any cases of human bovine tuberculosis imported from the Mediterranean but this remains a potential hazard.-N S GALBRAITH, director of PHLS Communicable Disease Surveillance Centre, London.
There is much anecdotal evidence that in the prepartum and postpartum periods femoral thrombosis or embolism not infrequently follows a warm bath. Has this been investigated?

Pregnancy increases the risk of venous thromboembolism because it causes stasis in the leg veins and raises the circulating levels of clotting factors. ${ }^{1}$ Theoretically either of these factors could be affected by a warm bath. Immersion in a deep bath causes relaxation of peripheral veins that persists after the immersion is over. ${ }^{2}$ External temperature affects some haemostatic factors: there is a positive correlation between fibrinolytic activity and temperature, which would tend to prevent thrombosis at higher temperatures. ${ }^{3}$ Investigation of postoperative bathing has concentrated on its effect on wound healing, but in a small series no thromboembolic complications were reported. ${ }^{+}$There have been several studies of the epidemiology of thromboembolism in pregnancy' but so far as I can tell none of the reports mentions this phenomenon.-JAMES OWEN DRIFE, senior lecturer in obstetrics and gynaecology, Leicester.

I Bolan JC. Thromboembolic complications of pregnancy. Clin Obstet Gynecol 1983;26:913-22. 2 Echt M, Lange $\mathrm{L}$, Gauer $\mathrm{OH}$. Changes in peripheral venous tone and central transmural venous pressure during immersion in a thermo-neutral bath. Pflugers Arch 1974;352:211-7.

Bull GM, Brozovic M, Chakrabarti R, et al. Relationship of air temperature to various chemical, haematological, and hacmostatic variables. $J$ Clin Pathol 1979;32:16-20

4 Fraser I, Askew A, Biles J, Pinchin J. Prospective randomised trial of early postoperative bathing. Br Med J 1976; i: 1506-7. 